\title{
Genus Gelastorhinus Brunner-Wattenwyl (Orthoptera: Acridoidea) in China with description of a new species
}

\author{
Ying Lu, Liming Wang \& Bingzhong Ren*
}

Lu, Y., Wang, L. M. \& Ren, B. Z. 2013: Genus Gelastorhinus Brunner-Wattenwyl (Orthoptera: Acridoidea) in China with description of a new species. Entomol. Fennica 24: 117-121.

Anew species of the genus Gelastorhinus is described from Liaoning, China. The new species closely resembles Gelastorhinus filatus (Walker, 1870). In addition, an identification key for the Chinese species of Gelastorhinus is presented.

Y. Lu, Jilin Key Laboratory of Animal Resource Conservation and Utilization, School of Life Sciences, Northeast Normal University, Renmin Street 5268, Changchun, China, 130024; Plant Protection College, Shenyang Agricultural University, Dongling Road 120, Shenyang, China, 110866; E-mail: luy251 @nenu.edu.cn

L. M. Wang, College of Life Sciences, Xinyang Normal University, Chang'an road 237, Xinyang, China, 464000; E-mail:shkjqwlm@126.com

B. Z. Ren (*Corresponding author), Jilin Key Laboratory of Animal Resource Conservation and Utilization, School of Life Sciences, Northeast Normal University, Renmin Street 5268, Changchun, China, 130024; E-mail: bzren (a) $163 . c o m$

Received 7 March 2012, accepted 20 December 2012

\section{Introduction}

The genus Gelastorhinus was described by Brunner von Wattenwyl (1893). So far 22 species of Gelastorhinus have been described (Eades et al. 2012). They are mainly distributed in Southeast Asia, India, Myanmar, Sikkim and Africa. There are 6 species known in China, distributed in Sichuan, Fujian, Guangdong, Guangxi, Hong Kong and Taiwan. They respectively are: Gelastorhinus chinensis Willemse, 1932; Gelastorhinus filatus (Walker, 1870); Gelastorhinus rotundatus Shiraki, 1910; Gelastorhinus tonkinensis Willemse, 1951; Gelastorhinus dubia Willemse, 1932 and Gelastorhinus sinensis (Walker, 1871). In addition to these species, a new species is here described from China.

\section{Material and methods}

This study was carried out between 10.27.IX.2007 in Liaoning, China. During the field work, specimens of Gelastorhinus were collected and then prepared as museum material by standard methods. The specimens were diagnosed by comparing with the species given by keys (Walker 1870, Shiraki 1910, Willemse 1932, 1951). Figures and measurements were obtained using a Motic-D400 plotter.

With a specimen under the objective, and a drawing paper under the drawing arm, the specimen was observed directly in the eyepiece, and the track tip of a pencil box was simultaneously moved so that the tip tracked along the contour of the sample. 


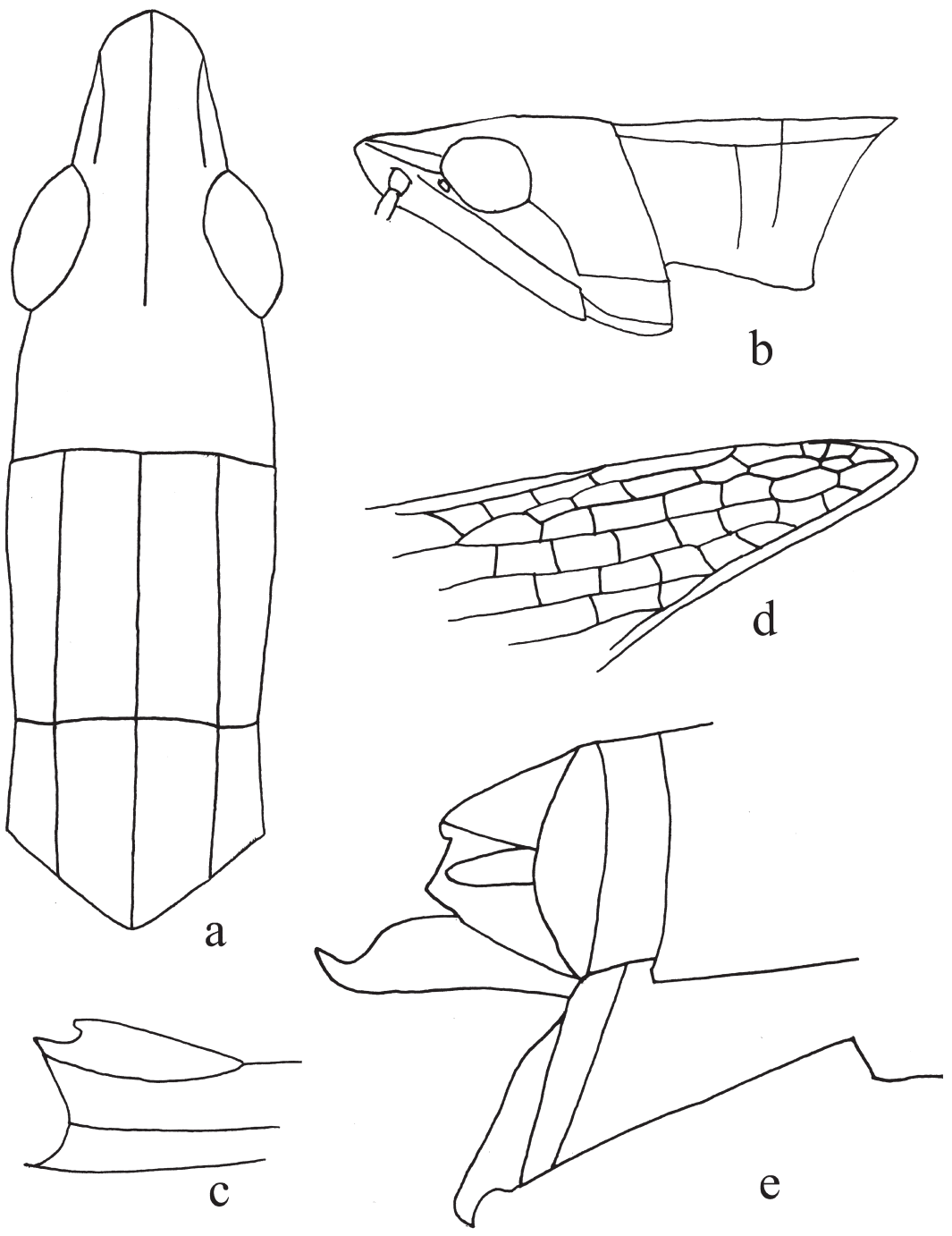

Fig.1. Gelastorhinus liaoningensis sp. $\mathbf{n}$. female. - a. Head and pronotum, dorsal view. - b. Head and pronotum, lateral view. - c. Knee of hind femur, lateral view. $-d$. Tegmen. - e. Cerci.
The following measurements (all in $\mathrm{mm}$ ) were taken in this study:

- Length of body (from tip of head to the end of abdomen)

- Longitudinal and horizontal diameter of compound eyes

- Distance between compound eyes

- Distance between antennae

- Length of subocular furrow

- Length of prozona

- Length of metazona

- Length of tegmina

- Length of hind femur

\section{Gelastorhinus Brunner-Wattenwyl,} 1893

Type-species: Gelastorhinus albolineatus Brunner-Wattenwyl, 1893.

Gelastorhinus Brunner-Wattenwyl, 1893: 137, 157.

Gelastorhinus Brunner-Wattenwyl, Kirby 1910: 409.

Gelastorhinus Brunner-Wattenwyl, Bei-Bienko \& Mishchenko 1951: 405.

Gelastorhinus Brunner-Wattenwyl, Johnston 1956: 635.

Gelastorhinus Brunner-Wattenwyl, Xia 1958: 95. 
Table 1. Comparison between female of Gelastorhinus filatus (Walker) and G. liaoningensis sp. $\mathbf{n}$.

\begin{tabular}{lll}
\hline Character & G. filatus & G. liaoningensis sp. $\mathbf{n}$. \\
\hline $\begin{array}{l}\text { Vertical diameter of eye/ } \\
\text { minimum width of vertex } \\
\text { between eyes }\end{array}$ & $1.5-1.9$ & 1.25 \\
$\begin{array}{l}\text { Length of the upper valvula } \\
\text { Antennae }\end{array}$ & $\begin{array}{l}\text { Longer than lower valvula } \\
\text { From basal first segments } \\
10 \text { to } 11 \text { flat, others rounded }\end{array}$ & $\begin{array}{l}\text { Same length or shorter } \\
\text { Basal segments } 2 \text { to } 11 \text { wide and flat }\end{array}$ \\
Mesostethium lobes & Separate narrowly & $\begin{array}{l}\text { The latter part almost connected } \\
\text { and separated only by a thin groove } \\
\text { Knee is green except upper kneelobes, } \\
\text { the rest part red }\end{array}$ \\
\hline
\end{tabular}

Gelastorhinus Brunner-Wattenwyl, Dirsh 1965: 409.

Gelastorhinus Brunner-Wattenwyl, Haskell 1982: 386.

Gelastorhinus Brunner-Wattenwyl, Zheng 1985: 387.

Gelastorhinus Brunner-Wattenwyl, Liu 1990: 174, 183-184.

Gelastorhinus Brunner-Wattenwyl, Zheng 1993: 375, 404-406.

Gelastorhinus Brunner-Wattenwyl, Liu et al. 1995: 114.

Gelastorhinus Brunner-Wattenwyl, Yin et al. 1996: 300.

\subsection{Key to the species of Gelastorhinus in China}

1. Posterior margin of pronotum nearly straight G. sinensis (Walker)

- Posterior margin of pronotum arcuate 2

2. Tegmen long and narrow, its apex acute 3

- Tegmen short and wide, its apex round 5

3. Long spine on upper kneelobes of inner side of hind femur. Its length about 2 times that of the upper kneelobes of outer side

G. chinensis Willemse

- Short spine on upper kneelobes of inner side of hind femur. Its length equal to or much shorter than that of the upper kneelobes of outer side

4. Lower valvula much shorter than upper valvula

G. filatus (Walker)
- Lower valvula not shorter than upper valvula G. liaoningensis sp.n.

5. Hind knee dark brown

- Hind knee black G. dubia Willemse

6. Tegmina short, nearly surpassing hind femur, apex rounded. Apex of cerci slightly expanded and rounded G. rotundatus Shiraki

- Tegmina long, surpassing beyond hind femur, apex acute. Apex of cerci not expanded, slender

G. tonkinensis Willemse

\subsection{Description of Gelastorhinus liaoningensis sp. n. female (Fig. 1)}

Type material. Holotype, 1: Collected from Suizhong county, Huludao city, Liaoning province (N40¹9'36", E120²0'25”) by Liming Wang and Ying Lu, 21.IX. 2007. Paratype, 1 \%: Same data as the holotype. The type specimens are deposited in Department of Biology, School of Life Sciences, Northeast Normal University, China.

Diagnosis. The new species is similar to G. filatus, but differs from the latter as shown in Table 1.

Description. Head. Slightly shorter than pronotum from the dorsal view (Fig. 1a). Vertex promnient, flat and slightly concave with a median carina. Vertical diameter of eyes/minimum width of vertex 1.25, apex arc-shaped. Frons backwards oblique, with deep longitudinal sulcus along whole length, widening gradually from the bottom of median ocellus to clypeus.

Eyes oval, located near middle of posterior 
part of head, vertical diameter of eyes 1.65 times of horizontal diameter and 1.15 times subocular furrow.

Antennae sword-shaped, their basal part (segments 2-11) wide and flat, the rest columnar, surpassing the posterior margin of pronotum.

Thorax. Anterior margin of pronotum straight, posterior margin curve. Median carina tectiform, lateral carinae nearly parallel (Fig. 1a). Anterior transverse sulcus not tectiform. Median transverse sulcus nearly incise lateral carina, but not median carina. Posterior transverse sulcus tectiform, and incise the median carina and lateral carinae. Prozona 1.3 times of metazona (Fig. 1b).

The latter parts of mesostethium lateral lobes are almost connected and separated only by a thin groove. The latter parts of metasternum lateral lobes connected.

Tegmina developed, apex acute (Fig. 1d) and exceeding tip of abdomen. Procostal, costal and medial area of tegmina with intercalary veins. Hind wings developed and shorter than tegmina.

Hind femur short, not reaching end of abdomen. Upper carina of hind femur smooth. Upper kneelobes nearly rectangular-shaped (Fig. 1c), inner and outer lobes equal. Lower kneelobes acutely angle-shaped, lower margin flat. Inner side of hind tibia with 15 spines and the outer one with 13 spines, without outer apical spine.

Abdomen. Cerci cylindrical (Fig. 1e), almost reaching the top of the supra-anal plate. Valvula short, end hook-shaped. Lower valvula not shorter than upper one.

Coloration. Back of body red-brown, with a dark red-brown postocular band. Postocular band reaches the posterior margin of pronotum, and extends to the basal part of costal area. Procostal area and costal area of tegmina green, otherwise red-brown. Hind legs yellow-green. Knee green except upper kneelobes, the rest part red. Segmengtal venter of protarsus and mesotarsus lawngreen. Tarsus of hind legs lawngreen.

Measurements (mm). Holotype, 19 , Paratype 1 : : Body length: 41.86, 41.72; Pronotum length: 7.20, 7.11; Tegmina length: 41.76, 41.61; Hind femur length: $17.40,17.12$.

Etymology. The species name is derived from the place of origin.

\section{Discussion}

According to available data, species of Gelastorhinus are mainly distributed in tropical and subtropical climate zones. However, in our investigation we discovered Gelastorhinus in the temperate climate zone in Liaoning province. This discovery changed the former knowledge and has significance for studies of the distribution and migration habits of Gelastorhinus.

\section{References}

Bei-Bienko, G. Y. \& Mishchenko, L. L. 1951: (Acridoidea of the fauna of the USSR and adjacent countries. Parts 1 and 2). - Opred Faune SSSR. Moscov. 38, 40: 1667. [In Russian.]

Brunner von Wattenwyl, C. 1893: Revision du Systeme des Orthopteres et description des especies rapportees par M. Leonardo Fea de Birmanie. - Annali del Museo Civico di Storia Naturale di Genova (Ser. 2), 13: 137, 157.

Dirsh, V. M. 1965: The African genera of Acridoidea. Cambridge University Press. 579 pp.

Eades, D. C., Otte. D., Cigliano, M. M. \& Braun, H. 2012: Orthoptera Species File Online. - Version 2.0/3.3. http://Orthoptera Species File.org). (Site visited on 21 May 2012.)

Haskell, P. T. 1982: The locust and grasshopper agricultural manual. - Centre for Overseas Pest Research, London, 690 pp.

Johnston, H. B. 1956: Annotated catalogue of African grasshoppers. - Cambridge University Press, AntiLocust Research Centre, 22: 833 pp.

Kirby, W. F. 1910: A synonymic catalogue of Orthoptera. - British Museum Catalogue of Orthoptera 3. Orthoptera Part ii (Locustidae Vel Acridiidae) vii, 674 pp.

Liu, J. P. 1990: A handbook for identifying grasshoppers of China. - Tianze Press, Shaanxi, China, 207 pp. [In Chinese.]

Liu, J. P \& Li, H. C. 1995: Studies on acridoids of Hainan Island. - Tianze Press, Shaanxi, China. 309 pp. [In Chinese with English summary.]

Shiraki, T. 1910: Acridiiden Japans. (Keiseisha). — Tokyo. 90 pp., 2 pls.

Walker, F. 1870: Catalogue of the Specimens of Dermaptera Saltatoria in the collection of the British Museum. Part III: 425-604. — British Museum, London.

Walker, F. 1871: Catalogue of the Specimens of Dermaptera Saltatoria in the collection of the British Museum, Supplement. - British Museum, London.

Willemse, C. 1932: Description of some new Acrididae (Orthoptera) chiefly from China from the Naturhistoriska Riksmuseum of Stockholm. - Natuurhistorich Maandblad Maastricht, 21: 104-107. 
Willemse, C. 1951: Synopsis of the Acridoidea of the IndoMalayan and adjacent regions (Insecta, Orthoptera). - Publicaties van het Natuurhistorisch genootschap in Limburg, 8: 3-225.

Xia, K. L. 1958: Taxonomic essentials of Acrididea from China. - Science Press, Beijing, China. 239 pp. [In Chinese.]

Yin, X. C., Shi, J. P. \& Yin, Z. 1996: A synonymic catalogue of grasshoppers and their allies of the world
(Orthoptera: Cealifera). — China Forestry Publishing House, Beijing. 1266 pp.

Zheng, Z. M. 1985: (Acridoidea from Yunnan, Guizhou, Sichuan, Shaanxi and Ningxia). - Science Press, Beijing. 406 pp. [In Chinese.]

Zheng, Z. M. 1993: (Taxonomy of Acridoidea). — Shaanxi Normal University Press, Xi'an, China. 400 pp. [In Chinese.] 